\title{
Article \\ Gendered Poverty Perceptions: How Do Retired Women Fare?
}

\author{
Bomikazi Zeka (1)
}

check for

updates

Citation: Zeka, Bomikazi. 2022

Gendered Poverty Perceptions: How

Do Retired Women Fare? Risks 10: 29

https://doi.org/10.3390/

risks10020029

Academic Editor: Cassandra Cole

Received: 19 November 2021

Accepted: 24 January 2022

Published: 28 January 2022

Publisher's Note: MDPI stays neutral with regard to jurisdictional claims in published maps and institutional affiliations.

Copyright: (C) 2022 by the author. Licensee MDPI, Basel, Switzerland. This article is an open access article distributed under the terms and conditions of the Creative Commons Attribution (CC BY) license (https:// creativecommons.org/licenses/by/ $4.0 /)$.
Canberra Business School, Faculty of Business, Government and Law, University of Canberra, 11 Kirinari Street, Canberra 2617, Australia; bomikazi.zeka@canberra.edu.au

\begin{abstract}
This paper examines the poverty perceptions of retired women by assessing the extent to which demographic characteristics, economic considerations, household adequacy levels and satisfaction measures influence perceptions of poverty. Based on data from a South African national survey, binomial logistic regression models were employed, whereby demographic characteristics (first level variables) were assessed relative to the respondents' poverty perceptions. Thereafter, economic considerations (second level variables) were included in the model to draw more inferences on the conditions leading to poverty perceptions. Finally, respondents' household adequacy levels and satisfaction measures (third level variables) were nested into the model for a complete investigation of the antecedents of poverty perceptions. Many of the retired women in this study perceive themselves to be impoverished or at risk of poverty. The results indicate that marital status and education levels have a significant influence on perceptions of poverty. Furthermore, the study found that monetary measures do not sufficiently explain the pathway leading to retirement poverty perceptions. Instead, perceptions of financial security and the satisfaction with one's standard of living influence gendered poverty perceptions. This study advances our understanding of the conditions influencing the poverty perceptions of retired women. As most of the respondents in this sample rely on the government for financial support, this study provides pertinent suggestions to government agencies on the conditions associated with gendered poverty perceptions at retirement.
\end{abstract}

Keywords: financial security; gendered poverty; living standards; retirement risk; socioeconomic conditions

\section{Introduction}

With the rise in longevity rates among the ageing population, many retirees are experiencing a deficit in their retirement savings, and this results in the impending likelihood of experiencing poverty during retirement (Bui et al. 2020). Although poverty-related studies have identified low-paid employment or unemployment as a precursor to poverty during retirement, the elderly are steadily growing in number as the second group most likely to live below the poverty threshold (Bilton et al. 2002; Sánchez-Sellero and Garcia-Carro 2020). Although past studies have assessed the proportion of a population that is living below the poverty line, socioeconomic factors provide an indication of the conditions that allude to poverty during retirement, including income inequalities, gender differences, insecure or seasonal work throughout one's lifecycle, the absence of support from family networks and limited access to affordable health care. These socioeconomic conditions impact how individuals spend, save, invest, and manage the risks of protecting their standards of living in their retirement years (Solaymani et al. 2019; Nyangarika and Bundala 2020). Understanding the key roles these play enables a more sophisticated analysis of the financial insecurity of individuals during retirement. As such, individual's perceptions of their experiences of poverty should be understood as multi-dimensional (Bilton et al. 2002; Solaymani et al. 2019; Sánchez-Sellero and Garcia-Carro 2020).

Previous studies have reported that women are the largest constituents of low-paid employees (Kock and Yoong 2011, p. 866; Burn et al. 2020), and experience further economic inequality when re-entering the labour market after a career disruption. Although 
the socioeconomic circumstances of women account for retirement poverty, this study argues that a partial picture is painted when only socioeconomic conditions are considered. Beyond the traditional socioeconomic approach of examining social security entitlements, income inequalities and age discrimination practices (Sawyer and James 2018; Burn et al. 2020; Clark et al. 2021), this paper advocates for the inclusion of household adequacy levels and satisfaction measures to provide a more holistic approach in examining the conditions that are associated with gendered poverty perceptions. Therefore, the aim of this paper is to determine the conditions that influence women's perceptions of retirement poverty, by investigating the extent to which demographic characteristics, economic considerations, household adequacy levels and satisfaction measures influence gendered poverty perceptions.

Through theories such as the feminisation of poverty, we are informed that social divisions, in the form of gender differences and economic disadvantages, work against women. As gender divides remain entrenched in economic systems and structures, genderspecific poverty emerges. (Pearce 1978; Mutua 2000). Although this theory may inform us of the processes through which retired women come into poverty, it does not it illuminate us of the set of conditions that maintain the poverty perceptions of older women. Furthermore, it is important to consider the way in which women perceive their circumstances, as these perceptions inform us of how they manage, negotiate and navigate their lives, based on their views of their circumstances. Thus, Noone et al.'s (2010) 'Theoretical model of gendered pathways to retirement preparation' provides an initial basis to predict the relationship between socioeconomic status and retirement perceptions from a gendered perspective. However, in order to understand women's views and perceptions of retirement poverty, it is necessary to widen this framework to include perceptions of household adequacy levels and satisfaction measures (Bilton et al. 2002; Grobler 2016) as income inequality has a causal effect on the resources of a household and levels of satisfaction with a household's needs. Through the inclusion of household adequacy levels and satisfaction measures in terms of living standards and financial security (Litwin and Sapir 2009; Cribb and Emmerson 2019; Burn et al. 2020), clearer insights on perceptions of gendered poverty are ascertained. Through the integration of these bodies of theory, this paper makes an important contribution in investigating the conditions associated with the poverty perceptions of retired women, particularly in the context of a developing country. As such, South Africa is used as the backdrop for this study.

\section{Theoretical Background and Research Questions}

\subsection{Perceptions of Gendered Retirement Poverty in South Africa}

Although academic debate agrees that poverty is a diverse, multi-dimensional and dynamic concept (Jansen et al. 2015; Sánchez-Sellero and Garcia-Carro 2020), poverty still relates to deprivations suffered in both monetary and non-monetary terms. In South Africa, poverty is on the rise, and in 2015, it was reported that half of the population was experiencing hardships that have pulled individuals and households into poverty (Francis and Webster 2019). Statistics South Statistics South Africa (2017) revealed that 43 per cent of South Africans aged 55 years and over were impoverished. These figures become more concerning as population estimates from South Africa indicate that the proportion of older persons (60 years and older) has grown from 7.6 per cent in 2002 to 9.1 per cent in 2020 (Statistics South Africa 2020a). This growth rate has implication from a broader economic point of view. In this regard, Rezaei (2021) states that the ageing population causes a decrease in national saving levels as a result of retirement, on the one hand, and can negatively affect economic growth through deteriorating labour force participation on the other. There is also a growing trend, particularly in developing countries, for the primary responsibility for providing an adequate retirement income for an individual to shift from governments and employers to the individuals. This creates a challenge for most individuals as high unemployment rates, wide income disparities and low savings rates, causes many individuals, particularly women, to perceive their economic 
and social security as undermined (Cohen-Mansfield and Regev 2011, p. 5; Farrell et al. 2016). Furthermore, women are also among those groups that experience a higher risk of poverty and social exclusion than the general population (Statistics South Africa 2020b). It is thus necessary to appreciate the circumstances under which the impoverished live, as these circumstances play an important role in shaping their perceptions of poverty (Davids and Gouws 2013). Moreover, understanding retired women's perceptions of marginalisation, social exclusion, and experiences of resource depravation is better comprehended through understanding their circumstance and living conditions (Reutter et al. 2005). For these reasons, the demographic characteristics, economic considerations, household adequacy levels and satisfaction measures of retired women are considered.

\subsection{Demographic Characteristics}

The extent to which individuals perceive financial insecurity during retirement can be viewed, in part, by their demographic characteristics. Poverty rates, as reported by Burn et al. (2020), are highest for older women who are unmarried or widowed, compared with those of married women. This signals that marital status plays a significant role in the likelihood of experiencing financial insecurity during retirement. In addition, individuals moving to larger cities for better employment opportunities has led to more people living in urban areas than in rural areas. Through this process of urbanisation, differences in poverty perceptions during retirement may occur (Davids and Gouws 2013; Solaymani et al. 2019). According to Hooyman et al. (2002), inequality among women is exacerbated by social class differences, as well as the types of pensions upon which they depend (Bilton et al. 2002). Prior studies have predicted that education directly impacts financial security in postretirement life (Cribb and Emmerson 2019; Murari et al. 2021), as individuals with higher levels of education are more likely to work in higher status occupations, earn more income and have more resources for retirement (Noone et al. 2010). Among these demographics, characteristics of individuals that are associated most with income inequality relate to race (Davids and Gouws 2013), where black women are reported to be more likely to encounter economic challenges that suppress their financial well-being (Burn et al. 2020).

\subsection{Economics Considerations}

Though the literature acknowledges how demographic characteristics can predict poverty in older age, the concept of older age is socially constructed. It is continually being redefined as a result of overall improvements in health, changes in social security provisions, and changing social norms regarding ageing. State provisions for older people are changing in response to these dynamics, given the increasing number of retirees who are dependent on government support (Bilton et al. 2002; Sawyer and James 2018). A substantial amount of literature on the socioeconomic aspect of ageing has focused on the growing number of retirees that fall into poverty (Cribb and Emmerson 2019; Solaymani et al. 2019; Clark et al. 2021), and women's experiences of career disruptions, spending time out of the labour market and inadequate financial opportunities (Bilan et al. 2020) all warrant consideration. These experiences over their lifetime have a threefold effect: on perceptions of retirement (Hershey et al. 2007), the decision of when to retirement (Topa et al. 2018) and their financial resources when entering retirement (Clark et al. 2021). Although the appreciation of financial resources is important, it is here, where in part, I argue that they cannot be viewed in isolation. Although it is necessary to ascertain how individuals can partially fulfil their needs through various sources of income, including pension grants and social security benefits (Wang et al. 2011), an incomplete assessment of the pathways leading to gendered poverty perceptions is paved. Alongside individual demographic characteristics and financial resources, poverty must also be viewed from a household perspective because a household's access to resources exerts a greater influence on individuals than an individual's access to resources on households. It is on this premise where I argue for the inclusion of perceptions of household resources and 
levels of satisfaction (or dissatisfaction) with the resources of the household in determining gendered poverty perceptions.

\subsection{Adequacy Levels and Satisfaction Measures}

Bilton et al. (2002) argued that if the provision for social security retirement benefits is significant and sustainable, retirement does not need to be associated with a significant drop in living standards. However, when a country's social security retirement benefit is means tested, as is the case in South Africa, it is often an inadequate source of income for retirees (Nevondwe 2010). This subsequently affects the ability to meet household needs and informs the perceptions of satisfaction or dissatisfaction with the resources of the household. Through the deprivation of basic needs, such as inadequate housing, a lack of access to healthcare services, food insecurity and inadequate levels of education within a household, evidence of poverty can be found (Collins et al. 2009; Nyangarika and Bundala 2020; Sánchez-Sellero and Garcia-Carro 2020). Prior studies (Litwin and Sapir 2009; Cribb and Emmerson 2019; Burn et al. 2020) uphold that perceptions of living standards and financial security act as antecedents for predicting the dominance of poverty perceptions.

Based on this theoretical underpinning, the following research questions were explored: (1) To what extent do retired South African women perceive themselves to be impoverished? (2) Which factors predict or inform their perceptions of poverty during retirement?

\section{Method}

\subsection{Data and Sample}

The research data were acquired through the most recent South African Social Attitudes Survey (SASAS) that captures topics relating to poverty, well-being, respondent and household characteristics, as well as personal and household income variables (Human Sciences Research Council 2017). This nationally representative and cross-sectional survey gathered information on the social conditions, financial well-being, public attitudes and behaviours of South Africans aged 16 years and older. This dataset has been employed in studies investigating the retirement savings adequacy of South Africans, published in the Journal of Financial Counselling and Planning (Reyers 2018). More recently, the dataset was also used to investigate perceptions of income inequality, which was published in Politikon (Roberts et al. 2021). The publication of these studies in the aforementioned reputable journals indicate the suitability of the dataset in this research. The questionnaires used to collect the data were paper-based and the respondents were randomly selected using a household roster.

To align with the objectives of this research, the sample was limited to retired female South African citizens. Therefore, criterion sampling was employed, whereby South African citizens were first identified. Thereafter, female respondents were selected. Finally, the retirement status of the respondents was determined based on the answer to the question: "What is your current employment status? (Which of the following best describes your present work situation?)". Those who selected "Pensioner (aged/retired)" formed part of the sample. Respondents that did not meet these criteria were excluded from the sample. Furthermore, respondents with missing data from any of the variables under investigation were removed, resulting in a sample of 325 respondents. Tabachnick and Fidell (2013) confirmed that a sample size with over 300 observations offers adequate statistical power for data analysis.

\subsection{Measures}

The outcome variable, Perceived poverty, was based on the answer to the question: "Would you say that you and your family are....". The subjective assessment of the respondent's poverty was measured using a 6-point scale ranging from (1) wealthy (2) comfortable (3) reasonably comfortable (4) just getting along (5) poor, and (6) very poor. To assist the 
data analysis procedure, non-poor (i.e., wealthy, comfortable and very comfortable) were coded 0 , and poor (i.e., just getting along, poor and very poor) were coded 1.

The predictor variables of the study included demographic characteristics, economic considerations, household adequacy levels and satisfaction measures.

The SASAS collected information relating to the demographic characteristics of the respondents. The age of the respondents was limited to individuals over age 60 , as this is the minimum retirement age at which South Africans can access employment-based retirement benefits or social security benefits (South African Social Security Agency 2021). Marital status was coded and divided into three categories: (1) married (2) widowed and (3) never married. The type of geographical area the respondents reside in was split into two categories: (1) Urban formal or informal and (2) Rural and traditional. The respondents also reported the social class that they belong to, which was categorised as follows: (1) lower class (2) working class (3) middle class and (4) upper class. The respondent's level of education was categorised as: (0) no schooling (1) primary education (2) some secondary education, excluding matric (i.e., final year of secondary school) (3) matric or equivalent and (4) tertiary education, in accordance with the South African education system (South Africans Qualifications Authority 2012). The SASAS solicited information relating to the race of the respondents and was separated into four categories: (1) Black African, (2) Coloured, (3) Indian/Asian and (4) White.

The economic considerations of the respondents comprised their access to government grant income, other sources of income and the value of their personal and household income. As such, recipients of the state pension grant were coded as: (1) Not a state pension grant recipient and (2) State pension grant recipient. Furthermore, the respondent's main sources of income were coded as: (1) Income from sources other than pensions or state grants and (2) Income from pensions and state grants. The total monthly household income of the respondents, before tax and other deductions, was separated into two categories: (1) <=ZAR7500 and (2) >ZAR7500. The total monthly personal income of the respondents, before tax and other deductions, was coded as: (1) <=ZAR2000 and (2) >ZAR2000.

The respondents' household adequacy levels were gauged relating to their housing, access to healthcare, children's schooling, and access to food (over the past month). The household adequacy levels were measured using a 3-point scale, with responses ranging from: 'it is not adequate for your household's needs' (1) to 'it is more than adequate for your household's needs' (3). To facilitate the data analysis procedure, these adequacy measures were separated into two categories and coded as follows: (1) inadequate and (2) adequate.

Satisfaction measures were assessed in terms of respondents' perceived financial security, perceived life satisfaction and perceived standard of living, using a 10-point response scale, whereby responses ranged from 'completely dissatisfied' (0) to 'completely satisfied' (10). Consequently, these measures of satisfaction were separated into three categories such that dissatisfied (i.e., completely dissatisfied (0) to moderately dissatisfied (3)) was coded as 1, neutral (i.e., slightly dissatisfied (4), neutral (5) and slightly satisfied (6)) was coded as 2 and satisfied (i.e., moderately satisfied (7) to completely satisfied (10)) was coded as 3.

\subsection{Data Analysis}

A t-test was undertaken to assess whether significant differences were present between the responses of male and female respondents, in relation to their perceptions of the outcome variable Perceived poverty. The t-test results indicated an asymptomatic significant difference in the responses of male and female respondents relating to their perceptions of poverty. In other words, female respondents perceived themselves to be more impoverished than their male counterparts (Asymp. Sig. 2-tailed $=0$ ) in line with previous studies (Mutua 2000; Litwin and Sapir 2009; Clark et al. 2021). As such, only female respondents ( $\mathrm{n}=325)$ formed the sample of this research.

To summarise the sample data, descriptive statistics were calculated on the demographic information of the respondents. An Exploratory Factor Analysis (EFA) was undertaken to assess the validity of the measuring instrument. Factor loadings of 0.4 or more 
provided fair evidence of validity (Wiid and Diggines 2013, p. 242). To extract the factors from the EFA, principal axis factoring was applied, and Promax with Kaiser Normalization was specified as the rotation method. The reliability of the measuring instrument was assessed through Cronbach's alphas, where Cronbach's alphas of at least 0.8 of more were accepted (Mitchell and Jolley 2010, p. 153).

One of the main uses of binomial logistic regression is that it estimates the probability of an event occurring (Domínguez-Almendros et al. 2011; Hosmer et al. 2013). Given the use of a dichotomous outcome variable Perceived poverty, a binomial logistic regression was appropriate to determine which variables were significant predictors of perceived poverty among retired South African women. Three sets of binomial regression analyses were conducted, whereby the respondents' demographic characteristics (Model 1) were used to predict poverty perceptions. Thereafter, the respondents' demographic characteristics were nested into their economic considerations (Model 2) to determine any changes to the predictive ability of the model. Finally, the respondents' household adequacy levels and satisfactions measures were then included to form Model 3. By nesting the models, additional inferences of the relationships investigated in this research were drawn and their predictive ability on the outcome variable (Perceived poverty) was determined.

Omnibus Tests of Model Coefficients were undertaken to assess overall statistical significance of each model. The percentage accuracy in classification (PAC) was reviewed to ascertain whether the overall prediction of cases into the observed categories of the outcome variable are improved by including the predictor variables. As such, the PAC for each model containing the predictor variables was compared with the base model PAC (in the case of this research, Model 1), to show the improvement in the model by adding in predictor variables. The Receiver Operating Characteristic (ROC) curve, which indicates the ability of a binomial logistic regression model to discern between respondents with or without the event of interest, was examined (Hosmer et al. 2013). In this paper, the event or outcome of interest relates to the respondent's perceptions of poverty. To determine model fit, Hosmer and Lemeshow goodness of fit tests were calculated. Furthermore, Cox and Snell R-squared values and Nagelkerke R-squared values were determined to ascertain the fitness of the predictive model. The software package SPSS version 23 was used to facilitate the data analysis procedure.

\section{Results}

\subsection{Description of the Demographic Characteristics and Economic Considerations of the Sample}

Most of the respondents indicated that they are black females over the age of 60 years $(52.30 \%)$, are widowed $(49.20 \%)$ and reside in urban areas $(76.30 \%)$. The majority of the respondents disclosed that their highest level of education is primary schooling (35.40\%) and perceive themselves to belong to the lower class (44.90\%). In addition, most of the respondents indicated that they receive a government pension grant $(84.90 \%)$, and the government pension grant is their main source of income $(76.90 \%)$. The majority of the respondents indicated that their total monthly household income is equal to or less than ZAR7500 (88.30\%) and their total monthly personal income is equal to or less than ZAR2000 $(88.60 \%)$.

An overview of the descriptive statistics of the remaining predictor variables (i.e., household adequacy levels and satisfactions measures) is provided in Table 1. 
Table 1. Descriptive statistics of the household adequacy levels and satisfaction measures of the sample $(n=325)$.

\begin{tabular}{lcc}
\hline & Frequency (\%) & Mean (SD) \\
\hline Housing adequacy & 80.90 & $1.19(0.39)$ \\
Inadequate (1) & 19.10 & \\
Adequate (2) & & $1.16(0.36)$ \\
\hline Healthcare adequacy & 84.60 & \\
Inadequate (1) & 15.40 & $1.09(0.29)$ \\
Adequate (2) & & \\
\hline Schooling adequacy & 91.10 & $1.15(0.36)$ \\
Inadequate (1) & 8.90 & \\
Adequate (2) & & $1.99(0.82)$ \\
\hline Food adequacy & 84.70 & \\
Inadequate (1) & 15.30 & \\
Adequate (2) & & \\
\hline Financial security & 34.20 & $2.43(0.75)$ \\
Dissatisfied (1) & 32.60 & \\
Neutral (2) & 33.20 & \\
Satisfied (3) & & \\
\hline Life satisfaction & 16.00 & \\
Dissatisfied (1) & 25.50 & \\
Neutral (2) & 58.50 & \\
Satisfied (3) & & \\
\hline Living standard & 20.00 & \\
Dissatisfied (1) & 31.70 & \\
Neutral (2) & 48.30 & \\
Satisfied (3) & 38.20 & \\
\hline Poverty perceptions & 61.80 & \\
Non-poor (0) & & \\
Poor (1) & & \\
\hline & & \\
\hline
\end{tabular}

\subsection{Results of the Validity and Reliability Analyses}

Bartlett's Test of Sphericity was significant $(p<0.001)$ for the variables with response scales. In addition, Kaiser-Meyer-Olkin values of 0.828 were returned, which indicated that the data were factor analysable.

The four items that related to household adequacy levels loaded together (i.e., "adequacy levels of your household's: housing, access to healthcare, children's schooling, and access to food over the past month"). The factor loadings ranged from 0.45 to 0.81 , thus providing sufficient proof of validity. The three items that related to satisfaction measures loaded together (i.e., "how satisfied are you with your financial security? how satisfied are you with your life as a whole? and how satisfied are you with your standard of living?"). Factor loadings for the satisfaction measures ranged from 0.58 to 0.92 , thus satisfying validity requirements.

All the items with response scales returned Cronbach's alpha coefficients greater than 0.81 , indicating satisfactory evidence of reliability. As multicollinearity can affect any regression model with more than one predictor, the Variance Inflation Factor (VIF) test was applied as it is acknowledged that correlations between the variables under investigation could exist. According to Kim (2019), a VIF result of less than 10 is an acceptable measure of the absence of high levels of multicollinearity. The VIF results from the data ranged from 1.32 to 6.10; therefore, the results confirmed the absence of multicollinearity in the data.

\subsection{The Results of the Binomial Logistic Regression Analyses}

Table 2 presents the results of the demographic characteristics of the respondents on the outcome variable Perceived poverty. 
Table 2. A binomial regression analysis on Perceived poverty (Model 1).

\begin{tabular}{|c|c|c|c|}
\hline${ }^{1}$ Predictor Variable (Code) & B (S.E.) & Sig. & $\operatorname{Exp}(B)$ \\
\hline Married (1) & $-0.958(0.449)$ & $0.033^{* *}$ & 0.384 \\
\hline Widowed (2) & $-0.568(0.424)$ & 0.18 & 0.567 \\
\hline Urban formal or informal (1) & $-0.691(0.464)$ & 0.136 & 0.501 \\
\hline Lower class (1) & $22.11(108)$ & 0.998 & 4000 \\
\hline Working class (2) & $21.335(108)$ & 0.998 & 1844 \\
\hline Middle class (3) & $20.573(108)$ & 0.998 & 8608 \\
\hline Primary education (1) & $2.961(1.162)$ & $0.011^{* *}$ & 19.319 \\
\hline Secondary education (2) & $3.871(1.111)$ & $0 * * *$ & 47.984 \\
\hline Matric (3) & $3.426(1.101)$ & $0.002^{* * *}$ & 30.746 \\
\hline Tertiary education (4) & $2.583(1.149)$ & $0.025^{* *}$ & 13.232 \\
\hline Black African (1) & $0.89(0.532)$ & 0.094 * & 2.436 \\
\hline Coloured (2) & $0.366(0.544)$ & 0.502 & 1.441 \\
\hline Indian/Asian (3) & $0.148(0.57)$ & 0.796 & 1.159 \\
\hline Cox and Snell $\mathrm{R}^{2}$ & 0.33 & & \\
\hline Nagelkerke $\mathrm{R}^{2}$ & 0.45 & & \\
\hline
\end{tabular}

The Omnibus Tests of Model Coefficients was undertaken where $p=0.00$ was returned, indicating the overall statistical significance of the test. The Hosmer and Lemeshow goodness of fit test was used to assess how poor the model is at predicting the categorical outcomes. For Model 1, the Hosmer and Lemeshow test was found to be statistically insignificant (chi-square $=6.71 ; \mathrm{df}=8$; sig. $=0.57$ ), thus providing evidence of model fit. The area under the ROC curve for Model 1 was 0.84, indicating an excellent level of discrimination between the groups, poor and non-poor (Hosmer et al. 2013).

The results from Table 2 indicate that married women $(\mathrm{b}=-0.958$; Wald $=4.558$; sig. $=0.033)$ are more likely to have perceptions of adequate financial resources during retirement, compared with widows and those who have never been married. Table 2 also shows a statistically significant relationship between levels of education and perceptions of poverty. Moreover, respondents who indicated they have lower levels of education were 47.984 times more likely to be classified as poor, relative to those with higher levels of education (i.e., tertiary education). The range of the confidence interval (95\% CI, 5.441 to 423.157) of this odds ratio illustrates that there is a wide range for the odds ratios. This is common when the data are sparse and there are unequal numbers of observations in each category. As such, crosstabulations calculations for each predictor variable with the outcome variable were performed to determine the patterns of the observations. Nevertheless, this limitation was addressed as evidence of consistency was present in the patterns of the odds ratios of the variables under investigation. Although the literature on poverty-related studies demonstrates that a lack of education leads to and sustains depravation, this study presents a contradictory finding. It is well documented that poverty is a multi-dimensional and complex construct. As such, one must consider that past experiences, including those of discrimination (Reutter et al. 2009), contribute towards the perception and presence of poverty. The sample of this study consists of older women who are recipients of the South African state pension. Despite the presence of education, the cumulative burden of gender, financial inequality and older age interplay and result in the conception of poverty. Furthermore, Table 2 shows that black retired women (Wald $=2.798$; sig. $=0.094$ ) are more likely to have perceptions of poverty during retirement compared with white, coloured, Indian and Asian women. The odds ratio indicates that black retired women are 2.436 ( $95 \%$ CI, 0.858 to 6.913 ) times more likely to be classified as poor, compared with white retired women. This finding aligns with previous research which reported that race had various effects throughout an individuals' life cycle (DiPrete and Eirich 2006; Melo et al. 2019), and even though highly educated, the marginal status of black people contributed towards their cumulative disadvantage. 
When the respondents' economic considerations are added to Model 1, a more elaborate assessment of the conditions relating to gendered poverty perceptions is established. Table 3 shows the results of the demographic characteristics and the economic considerations of the respondents in relation to the outcome variable Perceived poverty.

Table 3. A binomial regression analysis on Perceived poverty (Model 2).

\begin{tabular}{llll}
\hline${ }^{2}$ Predictor Variable (Code) & B (S.E.) & Sig. & Exp (B) \\
\hline Married (1) & $-1.091(0.46)$ & $0.018^{* *}$ & 0.336 \\
Widowed (2) & $-0.629(0.436)$ & 0.149 & 0.533 \\
Urban formal or informal (1) & $-0.754(0.472)$ & 0.11 & 0.47 \\
Lower class (1) & $21.806(108)$ & 0.998 & 295 \\
Working class (2) & $21.261(108)$ & 0.998 & 171 \\
Middle class (3) & $20.367(108)$ & 0.998 & 700 \\
Primary education (1) & $2.91(1.225)$ & $0.018^{* *}$ & 18.35 \\
Secondary education (2) & $3.807(1.17)$ & $0.001 * * *$ & 45.014 \\
Matric (3) & $3.293(1.149)$ & $0.004^{* * *}$ & 26.935 \\
Tertiary education (4) & $2.6(1.191)$ & $0.029 * *$ & 13.462 \\
Black African (1) & $0.757(0.569)$ & 0.183 & 2.132 \\
Coloured (2) & $0.293(0.592)$ & 0.621 & 1.34 \\
Indian / Asian (3) & $0.294(0.616)$ & 0.633 & 1.342 \\
State pension grant recipient $(2)$ & $0.137(0.522)$ & 0.793 & 1.147 \\
Income from sources other than & $-0.864(0.367)$ & $0.019 * *$ & 0.422 \\
pension or state grant (1) & $0.182(0.498)$ & 0.714 & 1.2 \\
Household income $<=$ ZAR7500 (1) & $0.168(0.457)$ & 0.712 & 1.183 \\
Personal income $<=$ ZAR2000 (1) & 0.34 & & \\
Cox and Snell R ${ }^{2 *}$ & 0.46 & & \\
Nagelkerke R & & &
\end{tabular}

Overall, Model 2 proved to be statistically significant as the Omnibus Tests of Model Coefficients returned a $p$-value of 0.00 . Prior to the inclusion of the economic considerations of the respondents, the PAC for Model 1 was 62 per cent. Model 2 returned a PAC of 76.5 per cent, indicating that by adding economic considerations, the predictive ability of the model improved. Furthermore, the improvement of the R-squared values (Cox and Snell and Nagelkerke) in Model 2 highlights a marginally better fit between the predictors and outcome variable of Perceived poverty. The area under the ROC curve for Model 2 was 0.851, also indicating a superb level of discernment between groups (Hosmer et al. 2013).

Similar to the results from Table 2, it is highlighted in Table 3 that married women are more inclined to associate retirement with adequate resources, and education levels have a statistically significant relationship with perceptions of poverty. However, a negative beta $(b=-0.864)$ was returned from the predictor variable Income from sources other than pension or state grant, suggesting that respondents whose main source of income is from a state pension grant are more likely to associate retirement with being impoverished. In South Africa, the state pension grant is available only to those who have insufficient financial resources to support themselves upon reaching retirement (Satumba et al. 2017). Recipients of this grant thus rely primarily on government social assistance for retirement income. As such, the results indicate a statistically significant relationship $($ Wald $=5.539 ;$ sig. $=0.019$ ) between recipients of state pension grants and perceived poverty. It is interesting to note that the race of the respondents was no longer statistically significant when their economic considerations are taken into account. Considering that that close to 85 per cent of the sample depend on state pensions, these findings may suggest that race is neither a primary nor a persistent contributor to poverty perceptions when one depends on the government for financial support during retirement and that state pension is the only source of income.

As the objective of this research is to determine the conditions that lead to perceptions of gendered poverty in retirement, an examination is undertaken of the respondents' 
demographic characteristics, economic considerations, household adequacy levels and satisfaction measures (see Table 4).

Table 4. A complete binomial regression analysis on Perceived poverty (Model 3).

\begin{tabular}{|c|c|c|c|}
\hline${ }^{3}$ Predictor Variable (Code) & B (S.E.) & Sig. & $\operatorname{Exp}(B)$ \\
\hline Married (1) & $-1.276(0.593)$ & $0.031^{* *}$ & 0.279 \\
\hline Widowed (2) & $-0.881(0.565)$ & 0.119 & 0.415 \\
\hline Urban formal or informal (1) & $-0.62(0.571)$ & 0.278 & 0.538 \\
\hline Lower class (1) & $20.924(107)$ & 0.998 & 122.00 \\
\hline Working class (2) & 21.275 (107) & 0.998 & 173.00 \\
\hline Middle class (3) & $19.4(107)$ & 0.999 & 266.00 \\
\hline Primary education (1) & $1.62(1.285)$ & 0.207 & 5.054 \\
\hline Secondary education (2) & $3.401(1.182)$ & $0.004^{* * *}$ & 29.979 \\
\hline Matric (3) & $3.181(1.172)$ & $0.007^{* * *}$ & 24.077 \\
\hline Tertiary education (4) & $2.699(1.218)$ & $0.027^{* *}$ & 14.871 \\
\hline Black African (1) & $0.623(0.725)$ & 0.391 & 1.864 \\
\hline Coloured (2) & $0.485(0.745)$ & 0.515 & 1.624 \\
\hline Indian/Asian (3) & $0.589(0.749)$ & 0.431 & 1.803 \\
\hline State pension grant recipient (2) & $-0.278(0.627)$ & 0.658 & 0.757 \\
\hline $\begin{array}{l}\text { Income from sources other than pension } \\
\text { or state grant (1) }\end{array}$ & $-0.379(0.442)$ & 0.392 & 0.685 \\
\hline Household income $<=$ ZAR7500 (1) & $0.596(0.611)$ & 0.329 & 1.816 \\
\hline Personal income $<=$ ZAR2000 (1) & $0.168(0.557)$ & 0.763 & 1.183 \\
\hline Housing inadequacy (1) & $0.57(0.642)$ & 0.375 & 1.768 \\
\hline Healthcare inadequacy (1) & $0.819(0.731)$ & 0.263 & 2.269 \\
\hline Schooling inadequacy (1) & $1.7(0.759)$ & $0.025^{* *}$ & 5.475 \\
\hline Food inadequacy (1) & $0.613(0.63)$ & 0.331 & 1.846 \\
\hline Dissatisfaction with financial security (1) & $1.229(0.541)$ & $0.023^{* *}$ & 3.419 \\
\hline Neutral about financial security (2) & $0.276(0.481)$ & 0.566 & 1.318 \\
\hline Dissatisfaction with life (1) & $0.18(0.807)$ & 0.824 & 1.197 \\
\hline Neutral about life satisfaction (2) & $0.646(0.518)$ & 0.212 & 1.908 \\
\hline Dissatisfaction with living standard (1) & $1.492(0.881)$ & $0.09 *$ & 4.447 \\
\hline Neutral about living standard (2) & $-0.169(0.493)$ & 0.731 & 0.844 \\
\hline Cox and Snell $\mathrm{R}^{2}$ & 0.39 & & \\
\hline Nagelkerke $\mathrm{R}^{2}$ & 0.53 & & \\
\hline
\end{tabular}

The Omnibus Tests of Model Coefficients for Model 3 was statistically significant as a $p$-value of 0.00 was generated. Additionally, the PAC increased from 76.5 per cent (Model 2) to 81.4 per cent (Model 3), indicating that the inclusion of household adequacy levels and satisfaction measures further improved the model's predictive ability. The improvement in the R-squared values (Cox and Snell and Nagelkerke) in Model 3 demonstrates an even better fit between the predictors and outcome variable of Perceived poverty. Thus, Model 3 was found to have the best model fit results as the Hosmer and Lemeshow test was found to be statistically insignificant (chi-square $=5.32 ; \mathrm{df}=8$; sig $=0.72$ ). The area under the ROC curve for Model 3 was 0.883 , which is an excellent level of discrimination according to Hosmer et al. (2013).

Table 4 illustrates that education and marital status are the only demographic characteristics that consistently have statistically significant relationships with the outcome variable Perceived poverty. More specifically, respondents with secondary schooling (Wald $=8.273$; sig. $=0.004)$, matric $($ Wald $=7.367$; sig. $=0.007)$ and tertiary education $($ Wald $=4.914$; sig. $=0.027$ ) are more likely to perceive themselves to experience poverty during retirement, as the cumulative disadvantage of retired women persists despite being educated. When household adequacy levels and satisfaction measures are nested into the model, the economic considerations of the respondents are no longer statistically significant.

The descriptive statistics showed that an overwhelming proportion $(91 \%)$ of the respondents indicated that they have inadequate levels of household schooling (see Table 1). 
This finding is echoed in Table 4 which shows that inadequate levels of schooling in the household (Wald $=5.019$; sig. $=0.025$ ) are associated with perceived poverty during retirement. These respondents with inadequate levels of household schooling were 5.475 (95\% CI, 1.237 to 24.232 ) times more likely to be classified as poor, relative to respondents with perceptions of adequate levels of household schooling.

Furthermore, the dissatisfaction with one's financial security was deemed statistically significant (Wald $=5.17$; sig. $=0.023$ ) with Perceived poverty. This suggests that respondents who indicated they were dissatisfied with their financial security were 3.419 (95\% CI, 1.185 to 9.863 ) times more likely to be classified as poor, relative to those who stated that they were satisfied with their financial security.

A further finding of this research relates to the perceptions of the respondents' standard of living. A statistically signification relationship (Wald $=2.872$; sig. $=0.09$ ) was found between the dissatisfaction with one's standard of living and Perceived poverty. As such, respondents that perceive their standard of living to be unsatisfactory were 4.447 (95\% CI, 0.792 to 24.978 ) times more likely to be classified as poor at retirement, relative to those that are satisfied with their standard of living.

\section{Discussion}

Indeed, the results of the study align with the literature that contends older women are most vulnerable to poverty during retirement (Burn et al. 2020; Sánchez-Sellero and GarciaCarro 2020; Statistics South Africa 2020b). The research established that over 60 per cent of the retired women in this study perceive themselves to be poor. Moreover, the specific interactions of their demographic characteristics, economic considerations, household adequacy levels and satisfaction measures inform their perceptions of poverty.

When only demographic characteristics are taken into consideration, married women are more likely to have perceptions of adequate resources during retirement. Furthermore, race plays a significant role in perceiving retirement poverty, particularly among black women. The level of education of the respondents predicts their perceptions of gendered poverty. Although a lack of education is expected to act as an antecedent of poverty, the cumulative disadvantage of black, retired older women on social welfare protects their marginal status (Melo et al. 2019). Additionally, the literature reports that educated women may be more aware of the risks associated with retirement (including but not limited to financial security) because of their schooling and training (Lee 2003).

In addition to demographic characteristics, economic considerations were also considered for a better understanding of the conditions leading to perceived poverty at retirement. With the inclusion of economic considerations, the study found that respondents depending on government pension grants were more likely to have perceptions of poverty at retirement, compared with retirees with additional sources of income. Marriage and education continued to inform poverty perceptions when economic considerations were included in predicting poverty perceptions. However, race did not contribute towards predicting gender-specific poverty during retirement when dependence on government pension grants for income was present.

When all four predictor variables are considered (i.e., demographic characteristics, economic considerations, household adequacy levels and satisfaction measures), the study found that education is consistently associated with perceptions of poverty. This presents an opportunity for future research to explore the impact and consequences of the cumulative disadvantage of retired women of colour. Interestingly, upon observation of the four predictor variable categories, economic considerations were not found to have a statistically significant relationship with perceptions of poverty. This confirms that poverty cannot be viewed solely from the perspective of economic deprivation. It also confirms that access to resources at a household level, rather than an individual level, exerts a greater influence on poverty perceptions. This research also established that respondents' perceptions of the inadequacy of household schooling and their dissatisfaction with their financial security and living standards led to perceptions of poverty. 


\section{Conclusions and Implications}

Retirement represents an important transition in individuals' lives, where individuals leave their employment and can access their retirement savings and social security retirement benefits to financially support themselves. At the same time, retirement is a concern for governments, due to its socioeconomic implications (Bloom et al. 2011). As more individuals are opting to retire early, more retirees are dependent on social security retirement benefits (Cribb and Emmerson 2019; Burn et al. 2020). Moreover, gender differences come into effect as the experiences of income inequality of women pre-retirement (Kock and Yoong 2011, p. 866) have a cumulative effect on their ability to fully self-fund their retirement years, thus increasing the risk of poverty during retirement.

The aim of this research was to investigate the conditions that influence retired women's perceptions of poverty. This study engaged with the demographic characteristics, economic considerations, household adequacy levels and satisfaction measures of retired women. These aspects were considered to predict and provide clearer insights on the perceptions of gendered poverty, as guided by the feminisation of poverty (Pearce 1978; Mutua 2000) and Noone et al. (2010) 'Theoretical model of gendered pathways to retirement preparation'. However, these frameworks provide a limited socioeconomic lens in capturing the circumstances that influence poverty perceptions. When household adequacy levels and satisfaction measures are encompassed, a greater appreciation of how women manage and negotiate their lives can be determined, particularly in managing perceptions of poverty (Bilton et al. 2002; Grobler 2016). The first contribution of this research thus relates to the inclusion of household adequacy levels and satisfaction measures in understanding the set of conditions that lead to the poverty perceptions of older women. Indeed, demographic traits and financial resources influence the way retirement is experienced (Sawyer and James 2018); however, that in itself does not account for the multi-dimension nature of gendered poverty. By integrating these bodies of theory, the study made another contribution to existing literature by investigating the conditions associated with the poverty perceptions of retired women, particularly in the context of a developing country. The final contribution of this research was made through nesting the demographic characteristics, economic considerations, household adequacy levels and satisfaction measures to predict gendered poverty perceptions. When these variables are nested, we can study how they interact to advance our understanding of the conditions leading to gendered poverty perceptions.

Using data from SASAS (Human Sciences Research Council 2017), retired South African women (over the age of 60 years) formed the sample of the study. The effect of the demographic characteristics, economic considerations, household adequacy levels and satisfaction measures on poverty perceptions were analysed through binomial logistic regression analyses. The pertinent results of the research suggest that access to education, at a household level, is paramount to mitigating the risk of poverty during retirement. This knowledge can assist policy makers to develop education-focused policies that not only target individuals but also their household, as adequate levels of education within a household may help eradicate retirement income insecurity and poverty among the older population. Furthermore, the cumulative disadvantage that retired women experience plays out in later life as constructs that are meant to be predictors of financial security at retirement, such as education, fail to negate poverty perceptions. This confirms the complex nature of poverty and warrants greater attention from policymakers so that the discriminatory experiences of older women can be corrected for improved social change.

Given that this research focused on women's perceptions of poverty, it is interesting to note that a national survey only had a representation of 325 retired women. The size of this sample further indicates the underrepresentation of retired women and the needs of this group. Government agencies responsible for collecting national data need to account for more retirees in national surveys. Without adequate representation of retired women, gendered poverty will remain underexplored, and poverty-related policies may fall short of capturing pertinent information on developing strategies that reduce gendered poverty. 
When all four predictor variables are considered (i.e., demographic characteristics, economic considerations, household adequacy levels and satisfaction measures), this study found that economic considerations do not influence poverty perceptions, despite the fact that 86 percent of the sample rely on government pension grants. This suggests that monetary measures do not entirely account for or explain women's perceptions of poverty during retirement. In fact, household adequacy levels and satisfaction measures provide more information on the conditions leading to gendered poverty, as the resources of a household, rather than individual resources, have the greatest ability to influence poverty perceptions. For these reasons, government agencies and policy makers should not only focus on the financial challenges of retirees but broaden the scope of investigation to include improving resources at a household level when addressing strategies on overcoming poverty at retirement.

Funding: This research received no external funding.

Institutional Review Board Statement: Not applicable as existing and publicly available secondary data was utilised for this research paper.

Informed Consent Statement: The study uses secondary data from a South African national survey that was curated by the Human Sciences Research Council of South Africa.

Data Availability Statement: The datasets generated by the survey research and analysed in the current study were last accessed on 8 September 2021 and are available from http://dx.doi.org/10.1 $4749 / 1575000020$.

Conflicts of Interest: The author declares no conflict of interest.

\section{Notes}

1 The omitted comparison categories for the variables included in the model are never married (marital status), rural and traditional (geographical area type), upper class (social class), no schooling (education), and white (race).

2 The omitted comparison categories for the variables included in the model are never married (marital status), rural and traditional (geographical area type), upper class (social class), no schooling (education), white (race), not a state pension grant recipient (state pension grant recipiency status), income from pensions and state grants (main source of income), >ZAR7500 (household income), and >ZAR2000 (personal income).

3 The omitted comparison categories for the variables included in the model are never married (marital status), rural and traditional (geographical area type), upper class (social class), no schooling (education), white (race), not a state pension grant recipient (state pension grant recipiency status), income from pensions and state grants (main source of income), >ZAR7500 (household income), >ZAR2000 (personal income), adequate (household adequacy levels), satisfied (financial security), satisfied (life), and satisfied (living standard).

\section{References}

Bilan, Yuriy, Halyna Mishchuk, Natalia Samoliuk, and Viktoriia Mishchuk. 2020. Gender discrimination and its links with compensations and benefits practices in enterprises. Entrepreneurial Business and Economics Review 8: 189-203. [CrossRef]

Bilton, Tony, Kevin Bonnett, Pip Jones, Tony Lawson, David Skinner, Michelle Stanworth, and Andrew Webster. 2002. Introductory Sociology. Basingstoke: Palgrave Macmillan.

Bloom, David E., David Canning, and Günther Fink. 2011. Implications of Population Ageing for Economic Growth. Available online: http:/ / www.hsph.harvard.edu/program-on-the-global-demography-of-ageing/WorkingPapers/2011/PGDA_WP_64 .pdf (accessed on 30 August 2021).

Bui, Truc Thi Mai, Patrick Button, and Elyce G. Picciotti. 2020. Early evidence on the impact of coronavirus disease 2019 (COVID-19) and the recession on older workers. Public Policy and Ageing Report 30: 154-59. [CrossRef] [PubMed]

Burn, Ian, Patrick Button, Theodore. F. Figinski, and Joanne. S. McLaughlin. 2020. Why retirement, Social Security, and age discrimination policies need to consider the intersectional experiences of older women. Public Policy and Ageing Report 30: 101-6. [CrossRef]

Clark, Robert, Annamaria Lusardi, Olivia S. Mitchell, and Hallie Davis. 2021. Factors Contributing to Financial Well-Being among Black and Hispanic Women. The Journal of Retirement. [CrossRef]

Cohen-Mansfield, Jiska, and Irit Regev. 2011. Expectations and Impact of Retirement Preparation Programs. Available online: https: // transitionsinlaterlife.files.wordpress.com/2014/10/expectations_and_impact_of_retirement_preparation_programs.pdf (accessed on 17 September 2021). 
Collins, Daryl, Jonathan Morduch, Stuart Rutherford, and Orlanda Ruthven. 2009. Portfolios of the Poor: How the World's Poor Live on \$2 a Day. Princeton: Princeton University Press.

Cribb, Jonathan, and Carl Emmerson. 2019. Can't wait to get my pension: The effect of raising the female early retirement age on income, poverty and deprivation. Journal of Pension Economics and Finance 18: 450-72. [CrossRef]

Davids, Yul Derek, and Amanda Gouws. 2013. Monitoring perceptions of the causes of poverty in South Africa. Social Indicators Research 110: 1201-20. [CrossRef]

DiPrete, Thomas A., and Gregory M. Eirich. 2006. Cumulative advantage as a mechanism for inequality: A review of theoretical and empirical developments. Annual Review of Sociology 32: 271-97. [CrossRef]

Domínguez-Almendros, Sonia, Nicolás Benítez-Parejo, and Amanda Rocío Gonzalez-Ramirez. 2011. Logistic regression models. Allergologia et Immunopathologia 39: 295-305. [CrossRef]

Farrell, Lisa, Tim R. Fry, and Leonora Risse. 2016. The significance of financial self-efficacy in explaining women's personal finance behaviour. Journal of Economic Psychology 54: 85-99. [CrossRef]

Francis, David, and Edward Webster. 2019. Poverty and inequality in South Africa: Critical reflections. Development Southern Africa 36: 788-802. [CrossRef]

Grobler, Wynand C. 2016. Perceptions of poverty: A study of food secure and food insecure households in an urban area in South Africa. Procedia Economics and Finance 35: 224-31. [CrossRef]

Hershey, Douglas A., Kène Henkens, and Hendrik P. Van Dalen. 2007. Mapping the minds of retirement planners: A cross-cultural perspective. Journal of Cross-Cultural Psychology 38: 361-82. [CrossRef]

Hooyman, Nancy, Colette V. Browne, Ruth Ray, and Virginia Richardson. 2002. Feminist gerontology and the life course. Gerontology and Geriatrics Education 22: 3-26. [CrossRef]

Hosmer, David W., Jr., Stanley Lemeshow, and Rodney X. Sturdivant. 2013. Applied Logistic Regression. Hoboken: John Wiley \& Sons, vol. 398.

Human Sciences Research Council. 2017. South African Social Attitudes Survey (SASAS) 2017: Questionnaire 1—All Provinces. Available online: https:/ / repository.hsrc.ac.za/handle/20.500.11910/15127 (accessed on 21 February 2020).

Jansen, Ada, Mariana Moses, Stanford Mujuta, and Derek Yu. 2015. Measurements and determinants of multifaceted poverty in South Africa. Development Southern Africa 32: 151-69. [CrossRef]

Kim, Jong Hae. 2019. Multicollinearity and misleading statistical results. Korean Journal of Anaesthesiology 72: 558. [CrossRef]

Kock, Tan Hoe, and Folk Jee Yoong. 2011. Knowing when to retire: The first step towards financial planning in Malaysia. Educational Gerontology 37: 854-84. [CrossRef]

Lee, William Keng Mun. 2003. Women and retirement planning: Towards the "feminization of poverty" in an aging Hong Kong. Journal of Women \& Aging 15: 31-53.

Litwin, Howard, and Eliyahu V. Sapir. 2009. Perceived income adequacy among older adults in 12 countries: Findings from the survey of health, ageing, and retirement in Europe. The Gerontologist 49: 397-406. [CrossRef]

Melo, Sara, Joana Guedes, and Sandra Mendes. 2019. Theory of cumulative disadvantage/advantage. Encyclopedia of Gerontology and Population Aging, 1-8. [CrossRef]

Mitchell, Mark L., and Janina M. Jolley. 2010. Research Design Explained, 7th ed. Belmont: Cengage Learning.

Murari, Krishna, Shalini Shukla, and Bhupendra Adhikari. 2021. Do psychological social and financial perceptions of post-retirement life and demography influence the retirement planning behaviour? International Journal of Social Economics. [CrossRef]

Mutua, Athena. 2000. Why retire the feminization of poverty construct. Denver Law Review 78: 1179.

Nevondwe, Lufuno. 2010. South African social security and retirement reform: A long journey towards the redrafting of the new Pension Funds Act. Pensions: An International Journal 15: 287-96. [CrossRef]

Noone, Jack H., Fiona Alpass, and Christine Stephens. 2010. Do men and women differ in their retirement planning? Testing a theoretical model of gendered pathways to retirement preparation. Research on Ageing 32: 715-38. [CrossRef]

Nyangarika, Anthony, and Felician S. Bundala. 2020. Influence of Retirement Benefits and Its Impact on Socio-Economic Development of Retirees in Tanzania. International Journal of Advance Research and Innovative Ideas in Education 6: 1245-58.

Pearce, Diane. 1978. The feminization of poverty: Women, work, and welfare. Urban and Social Change Review 11: 28-36.

Reutter, Linda I., Gerry Veenstra, Miriam J. Stewart, Dennis Raphael, Rhonda Love, Edward Makwarimba, and Susan McMurray. 2005. Lay understandings of the effects of poverty: A Canadian perspective. Health \& Social Care in the Community 13: 514-30.

Reutter, Linda I., Miriam J. Stewart, Gerry Veenstra, Rhonda Love, Dennis Raphael, and Edward Makwarimba. 2009. “Who do they think we are, anyway?": Perceptions of and responses to poverty stigma. Qualitative Health Research 19: 297-311. [CrossRef]

Reyers, Michelle. 2018. Perceptions of retirement adequacy: Evidence from South Africa. Journal of Financial Counseling and Planning 29: 343-56. [CrossRef]

Rezaei, Ebrahim. 2021. Demographic changes and savings behavior: The experience of a developing country. Journal of Economic Studies. [CrossRef]

Roberts, Benjamin, Adam Cooper, Sharlene Swartz, and Andrea Juan. 2021. 'Minding the Just Gap': Perceptions of the Legitimacy of Income Inequality from the South African Social Attitudes Survey. Politikon 48: 1-18. [CrossRef]

Sánchez-Sellero, María Carmen, and Beatriz Garcia-Carro. 2020. Which Groups Have a Greater Risk of Poverty in Spain? Revija za Socijalnu Politiku 27: 19-36. [CrossRef] 
Satumba, Takunda, Amiena Bayat, and Seeraj Mohamed. 2017. The impact of social grants on poverty reduction in South Africa. Journal of Economics 8: 33-49. [CrossRef]

Sawyer, Anne-Maree, and Sara James. 2018. Are baby boomer women redefining retirement? Sociology Compass 12: e12625. [CrossRef]

Solaymani, Saeed, Negin Vaghefi, and Fatimah Kari. 2019. The multidimensional poverty measure among Malaysian employee provident fund (EPF) retirees. Applied Research in Quality of Life 14: 1353-71. [CrossRef]

South African Social Security Agency. 2021. Old Age Grant. Available online: https:/ / www.gov.za/services/social-benefits-retirementand-old-age/old-age-pension (accessed on 19 August 2021).

South Africans Qualifications Authority. 2012. Level Descriptors for the South African National Qualifications Framework. Available online: https:/ / www.saqa.org.za/sites/default/files/2019-11/level_descriptors.pdf (accessed on 19 August 2021).

Statistics South Africa. 2017. Poverty on the Rise in South Africa. Available online: http:/ / www.statssa.gov.za/?p=10334 (accessed on 17 September 2021).

Statistics South Africa. 2020a. Protecting South Africa's Elderly. Available online: http:/ /www.statssa.gov.za/?p=13445 (accessed on 17 September 2021).

Statistics South Africa. 2020b. Poverty in Perspective. Available online: https://www.parliament.gov.za/storage/app/media/1_ Stock/Events_Institutional/2020/womens_charter_2020/docs/05-03-2021/StatsSa_presentation.pdf (accessed on 17 September 2021).

Tabachnick, Barbara G., and Linda S. Fidell. 2013. Using Multivariate Statistics, 6th ed. Boston: Pearson.

Topa, Gabriela, Marco Depolo, and Carlos-Maria Alcover. 2018. Early retirement: A meta-analysis of its antecedent and subsequent correlates. Frontiers in Psychology 8: 2157. [CrossRef]

Wang, Mo, Kène Henkens, and Hanna van Solinge. 2011. Retirement adjustment: A review of theoretical and empirical advancements. American Psychologist 66: 3. [CrossRef]

Wiid, Jan, and Collin Diggines. 2013. Marketing Research, 2nd ed. Cape Town: Juta. 